Check for updates

Cite this: RSC Adv., 2019, 9, 37584

Received 21st October 2019

Accepted 4th November 2019

DOI: 10.1039/c9ra08604h

rsc.li/rsc-advances

\title{
Efficient detection of a biomarker for infant jaundice by a europium(III)-organic framework luminescence sensor $\dagger$
}

\author{
Ping $\mathrm{Xu},{ }^{\mathrm{a}}$ Han-Wen Yang, ${ }^{\mathrm{a}} \mathrm{Jia}-\mathrm{Li}$ Shi, ${ }^{\mathrm{a}}$ Bo Ding, ${ }^{\mathrm{a}}$ Xiao-Jun Zhao (D) *ab \\ and En-Cui Yang (iD) *a
}

\begin{abstract}
Efficient detection of excess bilirubin in human serum and urine is highly important for the early diagnosis of infant jaundice. A highly stable $\mathrm{Eu}(\mathrm{III})$-based microporous framework with bent $\{\mathrm{Eu}(\mathrm{COO})\}$ chains interconnected by pairs of T-shaped 4,4'-(4,4'-bipyridine-2,6-diyl)dibenzoate (bpydb ${ }^{2-}$ ) linkers, $\left\{\left[\mathrm{Eu}\left(\mathrm{H}_{2} \mathrm{O}\right)(\mathrm{HCOO})(\mathrm{bpydb})\right] \cdot\right.$ solvent $_{n}(1)$, was solvothermally synthesized and used as a chemical sensor for bilirubin response under clinically-applicable visible-light excitation. Due to the significant synergetic effect of the inner filter effect and photoinduced electron transfer, 1 can effectively probe trace amounts of bilirubin in aqueous solution through fluorescence decay with a strong quenching constant of $6.40 \times$ $10^{4} \mathrm{M}^{-1}$ and low detection limit of $1.75 \mu \mathrm{M}$. More importantly, a portable test paper made from 1 was further developed to achieve qualitative, naked-eye visualized differentiation for the biomarker in clinical applications. These interesting findings highlight the importance of the $\pi$-conjugated antenna ligand for clinically applicable Ln-MOF sensors.
\end{abstract}

\section{Introduction}

Bilirubin, an orange-yellow metabolic breakdown product of red blood cells, plays essential physiological and pharmacological roles for anti-oxygen free radicals and anti-lipid peroxidation. ${ }^{1,2}$ Normal accumulated bilirubin can pass through the liver and is eventually excreted out of the body via bile. However, high levels of bilirubin beyond $50 \mu \mathrm{mol} \mathrm{L}^{-1}$ are toxic, resulting in yellowing of the skin, jaundice, brain or liver damage, and even the death of newborns..$^{3-8}$ Thus, bilirubin serves as an important biomarker for clinically diagnosing infant jaundice or evaluating the liver function, in which a rapid and efficient response toward the excess bilirubin is of great urgency for the early diagnosis of infant jaundice.

To date, a variety of available methods including diazo, ${ }^{9}$ enzymatic, ${ }^{10}$ vanadate oxidation, ${ }^{11}$ electrochemical ${ }^{12}$ and fluorometric techniques ${ }^{13}$ have been consequently applied to

\footnotetext{
${ }^{a}$ Key Laboratory of Inorganic-Organic Hybrid Functional Material Chemistry, Ministry of Education, Tianjin Key Laboratory of Structure and Performance for Functional Molecules, College of Chemistry, Tianjin Normal University, Tianjin 300387, P. R. China.E-mail: encui_yang@163.com; xiaojun_zhao15@163.com

${ }^{b}$ Synergetic Innovation Center of Chemical Science and Engineering (Tianjin), Tianjin 300071, P. R. China

$\dagger$ Electronic supplementary information (ESI) available: binding mode of the ligand, FT-IR spectra, 3D stacking structure, TG curve, PXRD pattern, time-dependent emission spectra, fluorescence lifetime and quantum yield, as well as X-ray crystallographic files in CIF format for 1. CCDC 1920170 for 1. For ESI and crystallographic data in CIF or other electronic format see DOI: 10.1039/c9ra08604h
}

recognize bilirubin in human serum and urine samples. Most of these approaches are time-consuming, involve complicated pretreatment and depend on expensive instruments. Hence, simple, fast and effective assays with a highly sensitive and selective response to bilirubin are highly desirable. ${ }^{14-16}$ Very recently, luminescent lanthanide-based metal-organic frameworks (Ln-MOFs) have emerged as powerful chemical probes for differentiating harmful analytes due to their characteristically sharp emission, large Stokes shift, long fluorescence lifetime and quick response. ${ }^{17-19} \mathrm{In}$ fact, a large number of Eu/Tb-MOFs with bright red/green emissions have been designed by far through in-corporations of versatile chromophores, postsynthetic modfications as well as host-guest self-assembly strategy. ${ }^{20,21}$ These versatile Ln-MOFs have exhibited remarkable capability of distinguishing toxic $\mathrm{Pb}^{\mathrm{II}}$ and $\mathrm{Hg}^{\mathrm{II}}$ ions, ${ }^{22,23}$ biomarkers for Bacillus anthracis spores and carcinoid tumors, ${ }^{24,25}$ hazardous $\mathrm{SO}_{2}$ and $\mathrm{H}_{2} \mathrm{~S}$ gases,${ }^{26,27}$ nitroexplosives, ${ }^{28}$ pharmaceutical and bio-marcomolecules ${ }^{29}$ through photoinduced energy transfer (PET), resonance energy transfer (RET), ground state complex formation, inner filter effect (IFE) and so on. Unfortunately, to the best of our knowledge, most of these discrimination have been triggered under the excitation of highenergy ultraviolet light, which have severely restricted their large-scale clinical on-site detection. Nevertheless, the Ln-MOFderived sensors for bilirubin response have been scarcely reported. ${ }^{13-16,30}$ Herein, to gain a clinical applicable sensor for bilirubin recognization, a crystalline europium(III)-based MOF, $\left\{\left[\mathrm{Eu}\left(\mathrm{H}_{2} \mathrm{O}\right)(\mathrm{HCOO})(\mathrm{bpydb})\right] \cdot\right.$ solvent $_{n}$ (1), was solvothermally generated by incorporation of a bulky $\pi$-conjugated $4,4^{\prime}-\left(4,4^{\prime}-\right.$ 
bipyridine-2,6-diyl)dibenzoic acid $\left(\mathrm{H}_{2}\right.$ bpydb) as light-responsive ligand. As expected, possessing excellent thermal and environmental stability, 1 can emit bright red luminescent under the irradiation of the low-energy visible light $\left(\lambda_{\mathrm{ex}}=432 \mathrm{~nm}\right)$, and can quickly and repeatedly distinguish trace amount of bilirubin through luminescent decay with strong quenching constant $\left(K_{\mathrm{sv}}=6.40 \times 10^{4} \mathrm{M}^{-1}\right)$ and low detection limit (1.75 $\mu \mathrm{M})$. More importantly, the convenient test paper was further fabricated from 1, which can successfully achieve a rapidly visual detection for bilirubin by naked eyes. All these favorable advantages make 1 be a promising luminescent probe for bilirubin response. Herein, solvothermal synthesis, crystal structure, thermal and environmental stability, sensing performance and application of $\mathbf{1}$ were reported in more details.

\section{Experimental}

\subsection{Materials and instruments}

All raw reagents were commercially available and used directly without further purification. $\mathrm{H}_{2}$ bpydb was synthesized according to the previous literature. ${ }^{31}$ Elemental analyses for $\mathrm{C}, \mathrm{H}$ and $\mathrm{N}$ were carried out on a CE-440 (Leeman-Labs) analyzer. Fourier transform (FT) IR spectra were performed on an Avatar370 (Nicolet) spectrometer with $\mathrm{KBr}$ pellets in the 4000$400 \mathrm{~cm}^{-1}$ region. Thermogravimetric analysis (TGA) was recorded on a TA Q500 thermogravimetric analyzer from room temperature to $800{ }^{\circ} \mathrm{C}$, with a heating rate of $5{ }^{\circ} \mathrm{C} \mathrm{min}^{-1}$ under nitrogen. Powder X-ray diffraction (PXRD) pattern was measured on a Rigaku D/max-2500 diffractometer at $60 \mathrm{kV}$ and $300 \mathrm{~mA}$ for $\mathrm{Cu} \mathrm{K} \alpha$ radiation $(\lambda=1.5406 \AA)$, with a scan speed of $0.2^{\circ} \cdot \mathrm{min}^{-1}$ and a step size of $0.02^{\circ}$ in the $2 \theta$ ranged from $5^{\circ}$ to $50^{\circ}$. Simulated PXRD pattern was calculated using single-crystal $\mathrm{X}$-ray diffraction data and Mercury v1.4 program available free of charge provided by the Cambridge Crystallographic Data Center. Optical images of the samples were taken on a Leica DM6 B upright digital research microscope from Leica microsystems. Fluorescence spectra were monitored on a Fluorolog-3 fluorescence spectrophotometer from Horiba Jobin Yvon at room temperature. Luminescence quantum yield and fluorescence lifetime were obtained by an FLS920 spectrofluorometer (Edinburgh Instruments) equipped with both continuous (450 W) xenon and pulsed flash lamps. UV-vis absorption spectra were recorded with a Shimadzu UV-2700 spectrophotometer.

\subsection{Synthesis of $\left\{\left[\mathrm{Eu}\left(\mathrm{H}_{2} \mathrm{O}\right)(\mathrm{HCOO})(\mathrm{bpydb})\right] \text {. solvent }\right\}_{n}$ (1)}

A mixture containing $\mathrm{Eu}\left(\mathrm{NO}_{3}\right)_{3} \cdot 6 \mathrm{H}_{2} \mathrm{O}(44.6 \mathrm{mg}, 0.1 \mathrm{mmol})$, $\mathrm{H}_{2}$ bpydb (39.6 mg, $0.1 \mathrm{mmol}$ ), cyclohexanol (948.0 mg, $1.0 \mathrm{~mL}$ ), $\mathrm{HCl}\left(0.4 \mathrm{~mL}, 1.0 \mathrm{~mol} \mathrm{~L}^{-1}\right)$, DMF $(2.0 \mathrm{~mL})$, and doubly deionized water $(1.0 \mathrm{~mL})$ was sealed in a $23.0 \mathrm{~mL}$ Teflon-lined stainlesssteel autoclave. The autoclave was kept at $160{ }^{\circ} \mathrm{C}$ for $72 \mathrm{~h}$ under autogenous pressure. After the mixture was cooled to room temperature at a rate of $5.8^{\circ} \mathrm{C} \mathrm{h}^{-1}$, brown block-shaped crystals suitable for single-crystal X-ray diffraction were obtained and separated manually (yield: $65 \%$ based on $\mathrm{H}_{2}$ bpydb ligand). Anal. calcd for $\mathrm{C}_{25.75} \mathrm{H}_{20.75} \mathrm{~N}_{2.25} \mathrm{O}_{8.25} \mathrm{Eu}(\%)$ : $\mathrm{C}, 47.90 ; \mathrm{H}$, 3.24; N, 4.88. Found: C, 47.60; H, 3.15; N, 5.02. FT-IR ( KBr

pellet, $\mathrm{cm}^{-1}$ ): 3387 (br), 3045 (w), 1676 (s), 1594 (s), 1533 (s), 1409 (s), 1384 (s), 1326 (m), 1152 (w), 1089 (w), 1014 (w), 862 (w), $816(\mathrm{~m}), 791(\mathrm{~m}), 746(\mathrm{w}), 704(\mathrm{w}), 628(\mathrm{w}), 488(\mathrm{~m})$.

\subsection{Preparation of test paper}

The filter paper was cut into strips of $0.5 \mathrm{~cm} \times 1.0 \mathrm{~cm}$. The dispersion of $1\left(1.0 \mathrm{mg} \mathrm{mL}^{-1}\right)$ in water was carefully dropped on these strips. The resulting strips were left at room temperature and dried in air.

\subsection{X-ray single-crystal data collection and structure determination}

Diffraction intensities of $\mathbf{1}$ were collected on a Bruker APEX-II CCD diffractometer equipped with a graphite-monochromatic Mo $K \alpha$ radiation with a radiation wavelength of $0.71073 \AA$ by using the $\varphi-\omega$ scan technique at $296 \mathrm{~K}$. Semiempirical multiscan absorption corrections were applied by using SADABS. ${ }^{32}$ The program SAINT was used for the integration of the diffraction profiles. ${ }^{33}$ The structures were solved by direct methods and refined with full matrix least-squares techniques by the SHELXL-97 and SHELXS-204/7 programs. ${ }^{34}$ Anisotropic thermal parameters were assigned to all non-hydrogen atoms. A number of severely disordered solvent molecules existed in the MOF, which were speculated based on the electron counts calculated by PLATON software. ${ }^{35}$ These disorder solvents were removed by SQUEEZE during the structural refinement. The crystallographic data and selected bond lengths and angles for $\mathbf{1}$ were listed in Table 1 and Table 2, respectively.

\subsection{Luminescent sensing of 1}

Well-crashed crystalline product of $\mathbf{1}(30.0 \mathrm{mg})$ was immersed into the doubly distilled water $(100.0 \mathrm{~mL})$. The resulting mixture has been ultrasonicated for $10 \mathrm{~min}$ and aged for one hour to

Table 1 Crystal data and structure refinement for $1^{a}$

Empirical formula

$F_{\mathrm{w}}$

Cryst size (mm)

Crystsyst

Space group

$a(\AA)$

$b(\AA)$

$c(\AA)$

$V\left(\AA^{3}\right)$

$Z, D_{\mathrm{c}}\left(\mathrm{g} \mathrm{cm}^{-3}\right)$

$h / k / l$

$F(000)$

$\mu\left(\mathrm{mm}^{-1}\right)$

Reflections collected/unique

$R_{\text {int }}$

Data/restraints/params

$R_{1}^{a}, w R_{2}^{b}(I>2 \sigma(I))$

$R_{1}, w R_{2}$ (all data)

GOFonF $^{2}$

Largest diff. peak per hole $\left(\mathrm{e} \AA^{-3}\right)$

${ }^{a} R_{1}=\Sigma\left(|| F_{\mathrm{o}}|-| F_{\mathrm{c}}||\right) / \Sigma\left|F_{\mathrm{o}}\right| \cdot{ }^{b} w R_{2}=\left[\Sigma w\left(\left|F_{\mathrm{o}}\right|^{2}-\left|F_{\mathrm{c}}\right|^{2}\right)^{2} / \Sigma w\left(F_{\mathrm{o}}{ }^{2}\right)^{2}\right]^{1 / 2}$.

1

$\mathrm{C}_{25} \mathrm{H}_{17} \mathrm{~N}_{2} \mathrm{O}_{7} \mathrm{Eu}$ 609.36

$0.18 \times 0.14 \times 0.13$

Orthorhombic

Pbcn

19.0174(12)

$7.6764(5)$

$32.951(2)$

4810.4(5)

$8,1.683$

$-20,22 /-8,3 /-39,35$

2400

19.081

$10368 / 4258$

0.0752

$4258 / 0 / 317$

$0.0562,0.1370$

$0.0751,0.1504$

1.007

$2.75,-1.59$ 
Table 2 Selected bond lengths $(\AA)$ and angles (deg) for $1^{a}$

\begin{tabular}{llll}
\hline $\mathrm{Eu}(1)-\mathrm{O}(1)$ & $2.349(4)$ & $\mathrm{Eu}(1)-\mathrm{O}(5)$ & $2.378(5)$ \\
$\mathrm{Eu}(1)-\mathrm{O}(2)^{\# 2}$ & $2.439(5)$ & $\mathrm{Eu}(1)-\mathrm{O}(5)^{\# 1}$ & $2.453(5)$ \\
$\mathrm{Eu}(1)-\mathrm{O}(3)^{\# 3}$ & $2.452(5)$ & $\mathrm{Eu}(1)-\mathrm{O}(6)^{\# 1}$ & $2.606(6)$ \\
$\mathrm{Eu}(1)-\mathrm{O}(4)^{\# 3}$ & $2.568(5)$ & $\mathrm{Eu}(1)-\mathrm{O}(7)$ & $2.416(5)$ \\
$\mathrm{Eu}(1)-\mathrm{O}(4)^{\# 4}$ & $2.506(5)$ & & \\
$\mathrm{O}(1)-\mathrm{Eu}(1)-\mathrm{O}(2)^{\# 2}$ & $139.47(16)$ & $\mathrm{O}(4)^{\# 4}-\mathrm{Eu}(1)-\mathrm{O}(6)^{\# 1}$ & $117.91(17)$ \\
$\mathrm{O}(1)-\mathrm{Eu}(1)-\mathrm{O}(3)^{\# 3}$ & $83.29(17)$ & $\mathrm{O}(4)^{\# 3}-\mathrm{Eu}(1)-\mathrm{O}(6)^{\# 1}$ & $137.22(17)$ \\
$\mathrm{O}(1)-\mathrm{Eu}(1)-\mathrm{O}(4)^{\# 3}$ & $135.02(17)$ & $\mathrm{O}(5)-\mathrm{Eu}(1)-\mathrm{O}(2)^{\# 2}$ & $75.21(16)$ \\
$\mathrm{O}(1)-\mathrm{Eu}(1)-\mathrm{O}(4)^{\# 4}$ & $74.39(17)$ & $\mathrm{O}(5)-\mathrm{Eu}(1)-\mathrm{O}(3)^{\# 3}$ & $110.53(17)$ \\
$\mathrm{O}(1)-\mathrm{Eu}(1)-\mathrm{O}(5)^{\# 1}$ & $73.39(17)$ & $\mathrm{O}(5)-\mathrm{Eu}(1)-\mathrm{O}(4)^{\# 4}$ & $146.87(16)$ \\
$\mathrm{O}(1)-\mathrm{Eu}(1)-\mathrm{O}(5)$ & $136.77(18)$ & $\mathrm{O}(5)-\mathrm{Eu}(1)-\mathrm{O}(4)^{\# 3}$ & $68.16(17)$ \\
$\mathrm{O}(1)-\mathrm{Eu}(1)-\mathrm{O}(6)^{\# 1}$ & $79.55(19)$ & $\mathrm{O}(5)^{\# 1}-\mathrm{Eu}(1)-\mathrm{O}(4)^{\# 3}$ & $145.92(15)$ \\
$\mathrm{O}(1)-\mathrm{Eu}(1)-\mathrm{O}(7)$ & $77.33(18)$ & $\mathrm{O}(5)^{\# 1}-\mathrm{Eu}(1)-\mathrm{O}(4)^{\# 4}$ & $68.07(16)$ \\
$\mathrm{O}(2)^{\# 2}-\mathrm{Eu}(1)-\mathrm{O}(3)^{\# 3}$ & $111.12(17)$ & $\mathrm{O}(5)-\mathrm{Eu}(1)-\mathrm{O}(5)^{\# 1}$ & $105.53(16)$ \\
$\mathrm{O}(2)^{\# 2}-\mathrm{Eu}(1)-\mathrm{O}(4)^{\# 3}$ & $72.31(16)$ & $\mathrm{O}(5)-\mathrm{Eu}(1)-\mathrm{O}(6)^{\# 1}$ & $69.06(18)$ \\
$\mathrm{O}(2)^{\# 2}-\mathrm{Eu}(1)-\mathrm{O}(4)^{\# 4}$ & $71.80(16)$ & $\mathrm{O}(5)^{\# 1}-\mathrm{Eu}(1)-\mathrm{O}(6)^{\# 1}$ & $50.62(17)$ \\
$\mathrm{O}(2)^{\# 2}-\mathrm{Eu}(1)-\mathrm{O}(5)^{\# 1}$ & $73.72(16)$ & $\mathrm{O}(5)-\mathrm{Eu}(1)-\mathrm{O}(7)$ & $68.54(17)$ \\
$\mathrm{O}(2)^{\# 2}-\mathrm{Eu}(1)-\mathrm{O}(6)^{\# 1}$ & $97.13(18)$ & $\mathrm{O}(7)-\mathrm{Eu}(1)-\mathrm{O}(2)^{\# 2}$ & $142.33(16)$ \\
$\mathrm{O}(3)^{\# 3}-\mathrm{Eu}(1)-\mathrm{O}(4)^{\# 3}$ & $51.99(15)$ & $\mathrm{O}(7)-\mathrm{Eu}(1)-\mathrm{O}(3)^{\# 3}$ & $73.79(17)$ \\
$\mathrm{O}(3)^{\# 3}-\mathrm{Eu}(1)-\mathrm{O}(4)^{\# 4}$ & $79.15(16)$ & $\mathrm{O}(7)-\mathrm{Eu}(1)-\mathrm{O}(4)^{\# 4}$ & $142.69(17)$ \\
$\mathrm{O}(3)^{\# 3}-\mathrm{Eu}(1)-\mathrm{O}(5)^{\# 1}$ & $143.66(16)$ & $\mathrm{O}(7)-\mathrm{Eu}(1)-\mathrm{O}(4)^{\# 3}$ & $84.78(17)$ \\
$\mathrm{O}(3)^{\# 3}-\mathrm{Eu}(1)-\mathrm{O}(6)^{\# 1}$ & $150.87(17)$ & $\mathrm{O}(7)-\mathrm{Eu}(1)-\mathrm{O}(5)^{\# 1}$ & $125.38(17)$ \\
$\mathrm{O}(4)^{\# 4}-\mathrm{Eu}(1)-\mathrm{O}(4)^{\# 3}$ & $98.43(14)$ & $\mathrm{O}(7)^{\# 1}-\mathrm{Eu}(1)-\mathrm{O}(6)^{\# 1}$ & $79.56(18)$ \\
& & & \\
& & &
\end{tabular}

${ }^{a}$ Symmetry codes: ${ }^{\# 1} 1 / 2-x, 1 / 2+y, z ;{ }^{\# 2} 1 / 2-x, y-1 / 2, z ;{ }^{\# 3} 1-x, y-$ $1,3 / 2-z ;{ }^{\sharp 4} x-1 / 2, y-1 / 2,3 / 2-z ;{ }^{\# 5} 1-x, 1+y, 3 / 2-z ;{ }^{\# 6} 1 / 2+x, 1 / 2+$ $y, 3 / 2-z$.

obtain the uniform dispersion of $\mathbf{1}\left(0.3 \mathrm{mg} \mathrm{mL} \mathrm{L}^{-1}\right)$. For the luminescent sensing experiments, $200 \mu \mathrm{L}$ freshly prepared aqueous solutions including $\mathrm{MCl}_{x}\left(\mathrm{M}=\mathrm{K}^{+}, \mathrm{Na}^{+}, \mathrm{Ca}^{2+}, \mathrm{Fe}^{3+}, \mathrm{Fe}^{2+}\right.$ and $\mathrm{Zn}^{2+}, 1.0 \times 10^{-3} \mathrm{~mol} \mathrm{~L}^{-1}$ ), uric acid (UA), creatinine (Cre), creatine, glucose (Glu), ascorbic acid (AA), and bilirubin $(1.0 \times$ $10^{-3} \mathrm{~mol} \mathrm{~L}^{-1}$ ) were respectively added to the dispersion of 1 $\left(0.3 \mathrm{mg} \mathrm{mL}{ }^{-1}, 3.0 \mathrm{~mL}\right)$. The emission spectra of the resultant mixture were respectively recorded in the absence and presence of different analytes mentioned above. For fluorescence titration measurements, newly prepared aqueous solution of bilirubin $\left(1.0 \times 10^{-3} \mathrm{~mol} \mathrm{~L}^{-1}\right)$ was gradually introduced to the stock suspension of $\mathbf{1}\left(0.3 \mathrm{mg} \mathrm{mL}{ }^{-1}, 3.0 \mathrm{~mL}\right)$, and the emission spectra of the resultant mixture was respectively recorded. The interference experiments were carried out by monitoring the emission intensity of 1 at $616 \mathrm{~nm}$ upon stepwise introducing of bilirubin and one of the interfering substances.

\subsection{Recycling and regeneration of 1}

After each sensing experiment, the mixture was centrifugated to obtain the solid powder. The recovered powder was washed several times with distilled water and dried in air. Then, the regenerated $\mathbf{1}$ was reused in the succeeding experiments.

\subsection{Mott-Schottky measurement}

Electrochemical Mott-Schottky experiments were measured on an AMETEK Princeton Applied Research (Versa STAT 4) electrochemical workstation using complex 1/FTO combination as the working electrode, a platinum foil as the counter electrode, and a saturated $\mathrm{Ag} / \mathrm{AgCl} / \mathrm{KCl}$ as the reference electrode. The working electrode 1/FTO was prepared by dropping $50 \mu \mathrm{L}$ of sample suspension containing $1(1.5 \mathrm{mg})$, ethanol $(0.5 \mathrm{~mL})$ and Nafion $(10 \mu \mathrm{L})$ directly onto a FTO plate. The surface area of the working electrode exposed to the electrolyte was about $1.0 \mathrm{~cm}^{2}$. Mott-Schottky curves of $\mathbf{1}$ and bilirubin were respectively measured in $0.2 \mathrm{M} \mathrm{Na}_{2} \mathrm{SO}_{4}$ aqueous solution $(\mathrm{pH}=10)$ over the frequencies of 500, 1000, and $1500 \mathrm{~Hz}$.

\subsection{Inner filter effect (IFE) correction}

The role of IFE on the suppression of the fluorescence of $\mathbf{1}$ was calculated by Parker equation. $\mathrm{CF}=\frac{I_{\text {cor }}}{I_{\mathrm{obsd}}}=\frac{2.3 d A_{\mathrm{ex}}}{1-10^{-d A_{\mathrm{ex}}}} 10^{g A_{\mathrm{em}}} \frac{2.3 s A_{\mathrm{em}}}{1-10^{-s A_{\mathrm{em}}}}$, where CF is defined as corrected factor, $I_{\text {obsd }}$ refers to the measured fluorescence intensity of 1 at $616 \mathrm{~nm}$ under the excitation of $432 \mathrm{~nm}, I_{\text {cor }}$ is the corrected fluorescence intensity when IFE is removed from $I_{\mathrm{obsd}}, A_{\mathrm{em}}$ and $A_{\mathrm{ex}}$ are the absorbance of $\mathbf{1}$ having bilirubin at the excitation wavelength of $432 \mathrm{~nm}$ and emission wavelength of $616 \mathrm{~nm}, s$ refers to the thickness of the excitation beam $(0.1 \mathrm{~cm})$, $g$ refers to the distance between the edge of the excitation beam and the edge of the cuvette $(0.40 \mathrm{~cm})$, and $d$ refers to the width of the cuvette $(1.00 \mathrm{~cm}){ }^{36,37}$ The observed and corrected quenching efficiency ( $E_{\text {obsd }}$ and $E_{\text {cor }}$ ) were further calculated with the corresponding fluorescence intensity through $E=1-$ $I / I_{0}$.

\section{Results and discussion}

\subsection{Synthesis and FT-IR spectrum of 1}

Complex 1 was solvothermally synthesized at $160{ }^{\circ} \mathrm{C}$ in strongly acidic environment controlled by aqueous hydrochloric acid solution. Reaction temperature and medium were found to be important for the successful preparation of the crystalline product. Solvothermal temperature lowered than $160{ }^{\circ} \mathrm{C}$ made the crystal grain opaque, and the un-controlled medium cannot ensure the full protonation of $\mathrm{H}_{2}$ bpydb ligand.

A broad band centered at $3387 \mathrm{~cm}^{-1}$ in the IR spectrum of 1 is attributed to the $\mathrm{O}-\mathrm{H}$ stretching vibrations (Fig. $\mathrm{S} 1 \dagger$ ), suggesting the presence of the water molecule. A weak absorption at $3045 \mathrm{~cm}^{-1}$ is resulting from the stretching vibration of aromatic $\mathrm{C}-\mathrm{H}$ bond from phenyl and pyridyl moieties of bpydb ${ }^{2-}$ ligand. As compared with the isolated $\mathrm{H}_{2}$ bpydb molecule, an absence of a characteristic peak at $1718 \mathrm{~cm}^{-1}$ in 1 indicates that the carboxylic group attached on the phenyl ring is fully deprotonated. Characteristic multiple bands for asymmetric and symmetric stretching vibrations of $\mathrm{COO}^{-}$are observed at 1676, 1594, 1533, 1409 and $1384 \mathrm{~cm}^{-1}$. Thus, the IR results are consistent with the single-crystal structural determinations.

\subsection{Crystal structure of 1}

Single-crystal X-ray diffraction analysis reveals that 1 crystallizes in the orthorhombic Pbcn space group (Table 1), exhibiting an isolated microporous structure with formate-propagated $\{\mathrm{Eu}(\mathrm{COO})\}$ chains cross-linked by T-shaped bpydb ${ }^{2-}$ connectors. The asymmetric unit of 1 contains one $\mathrm{Eu}^{\mathrm{III}}$ ion, one doubly deprotonated bpydb ${ }^{2-}$ anion, one formate anion, one 
aqua ligand as well as disordered solvents (one water and a quarter of DMF). Notably, these solvent molecules are only identified by the PLATON squeeze program based on the electron counts. As shown in Fig. 1a, the unique Eu1 ion is in an $\mathrm{O}_{9}$ donor set surrounded by one terminally coordinated water molecule $(\mathrm{O} 7 \mathrm{~W})$, eight $\mathrm{O}_{\text {carboxylate }}$ donors from four separate bpydb $^{2-}(\mathrm{O} 1, \mathrm{O} 2 \mathrm{~B}, \mathrm{O} 3 \mathrm{C}, \mathrm{O} 4 \mathrm{C}$ and $\mathrm{O} 4 \mathrm{D})$ and two individual formate anions (O5, O5A and O6A). The coordination polyhedron of the $\mathrm{Eu}^{\mathrm{III}}$ ion can be described as a distorted muffin geometry with the CShM value of 1.558 evaluated by SHAPE software (Fig. 1a inset). ${ }^{38}$ The bond lengths of $\mathrm{Eu}-\mathrm{O}$ range from 2.349 (4) to $2.606(6) \AA$ (Table 2), comparable with the previously reported $\mathrm{Eu}^{\mathrm{III}}$-complexes with diverse carboxylate-derived ligands. ${ }^{25,39-41}$ The formate anion in $\mathbf{1}$ is solvothermally produced by the hydrolysis of $\mathrm{DMF}^{28}$ adopting a bidentate chelating-bridging coordination fashion $\left(\mu_{2}-\eta^{2}: \eta^{1}\right.$, Fig. S2 $\left.\dagger\right)$. By contrast, bulky $\pi$-conjugated bpydb ${ }^{2-}$ ligand is in a fully deprotonated form, exhibiting a $\mu_{4}-\eta^{1}: \eta^{1:} \eta^{2}: \eta^{1}$ manner to interact with lanthanide ions (Fig. S2 $\dagger$ ).

As shown in Fig. 1b, the separate $\mathrm{Eu}^{\mathrm{III}}$ ions are held together by three-atom $\mu_{2}-\eta^{2}: \eta^{1}-\mathrm{COO}^{-}$bridge, generating a zigzag chain running along the crystallographic $b$ axis with the shortest intrachain $\mathrm{Eu}^{\mathrm{III}} \cdot \mathrm{Eu}^{\mathrm{III}}$ distance of $4.0919(6) \AA$. The adjacent $\{\mathrm{Eu}(\mathrm{COO})\}$ chains are hold together by pairs of $\mathrm{bpydb}^{2-}$ connectors in a head-to-tail arrangement, resulting in a microporous framework with the nearest interchain $\mathrm{Eu}^{\mathrm{III}} \cdots \mathrm{Eu}^{\mathrm{III}}$ distance of 16.0968 (10) Å (Fig. 1b). Notably, the channels of 1

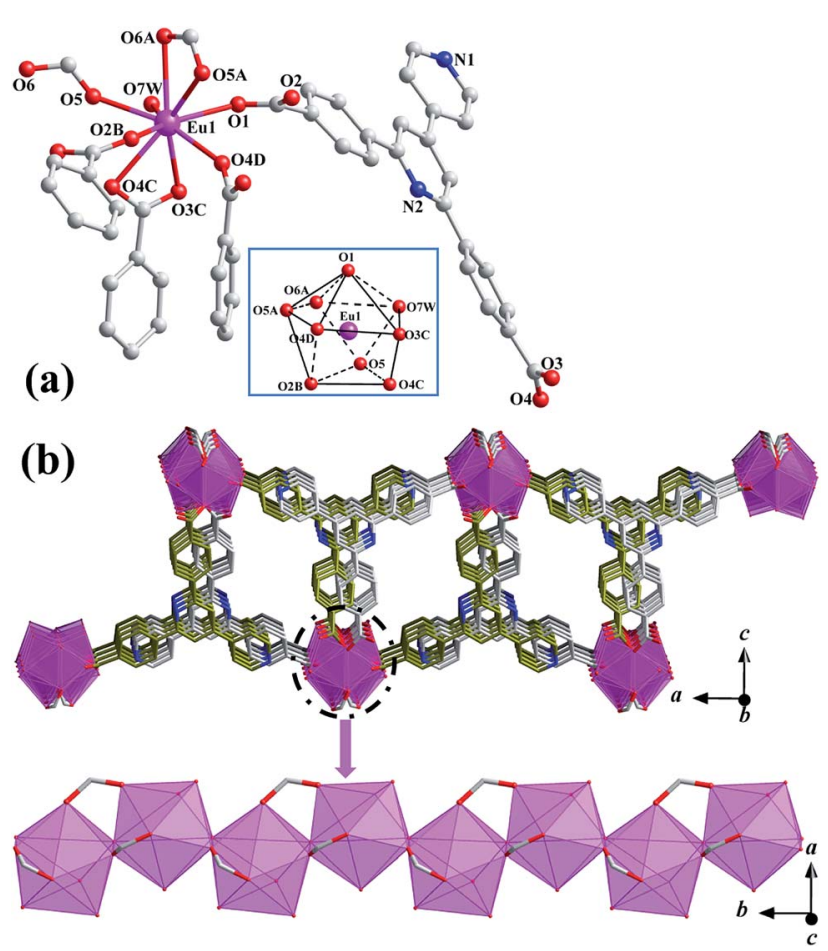

Fig. 1 (a) Local coordination environments and polyhedron of Eu'll ion in 1 ( $\mathrm{H}$ atoms were emitted for clarity, symmetry codes: $A=1 / 2-x, 1 / 2$ $+y, z ; B=1 / 2-x, y-1 / 2, z ; C=1-x, y-1,3 / 2-z ; D=x-1 / 2, y-1 /$ $2,3 / 2-z$ ). (b) Microporous framework of 1 extended in the crystallographic ac plane. are accommodate by one disordered water and a quarter of distorted DMF molecules deduced from the calculated electron number. The total potential solvent area volume and the porosity of 1 is $583.4 \AA^{3}$ and $12.1 \%$. These microporous frameworks of $\mathbf{1}$ are periodically stacked into a threedimensional (3D) supramolecular network through weak interlayer $\mathrm{C}-\mathrm{H} \cdots \mathrm{O}$ hydrogen-bonding interactions between the aromatic $\mathrm{C}-\mathrm{H}$ of bpydb ${ }^{2-}$ anion and the $\mathrm{COO}^{-}$anions (Table S1 and Fig. S3†).

\subsection{Phase-purity and stability of 1}

PXRD pattern of bulk as-synthesized 1 was well consistent with the simulated one produced by the single-crystal structural data (Fig. 2), suggesting high phase-purity and structural consistency of the as-prepared $\mathbf{1}$ with the single-crystal X-ray diffraction data. Compositional thermal stability and skeleton environmental stability of 1 were further examined by TGA and variabletemperature PXRD measurements (Fig. 2 and $\mathrm{S} 4 \dagger$ ). Both the disordered solvent and coordinated water molecules were released between $25{ }^{\circ} \mathrm{C}$ and $231{ }^{\circ} \mathrm{C}$, resulting in an obviously weight-loss of $8.8 \%$ (calcd. $8.4 \%$, Fig. $\mathrm{S} 4 \dagger$ ). The coordinated formate anion in $\mathbf{1}$ was then removed slowly upon further heating up to $422{ }^{\circ} \mathrm{C}$, accompanying with a weight-loss of $6.7 \%$ (calcd. 7.0\%). Once the temperature was higher than $500{ }^{\circ} \mathrm{C}$, the organic ligand was partially decomposed, which was not completely finished until $800{ }^{\circ} \mathrm{C}$.

Variable-temperature PXRD patterns of $\mathbf{1}$ after heating at $25{ }^{\circ} \mathrm{C}, 200{ }^{\circ} \mathrm{C}$ and $300{ }^{\circ} \mathrm{C}$ for two hours were consistent with the simulated one (Fig. 2). The environmental robustness was further checked by soaking the crystalline $\mathbf{1}$ in an aqueous solutions with $\mathrm{pH}=2,7$, and 12 for one day or immersing the crystalline 1 in boiling water for seven day. As a result, the PXRD patterns of 1 recovered from these surroundings were good consistent with that of the as-synthesized sample. These findings reveal that $\mathbf{1}$ has the excellent composition, thermal and

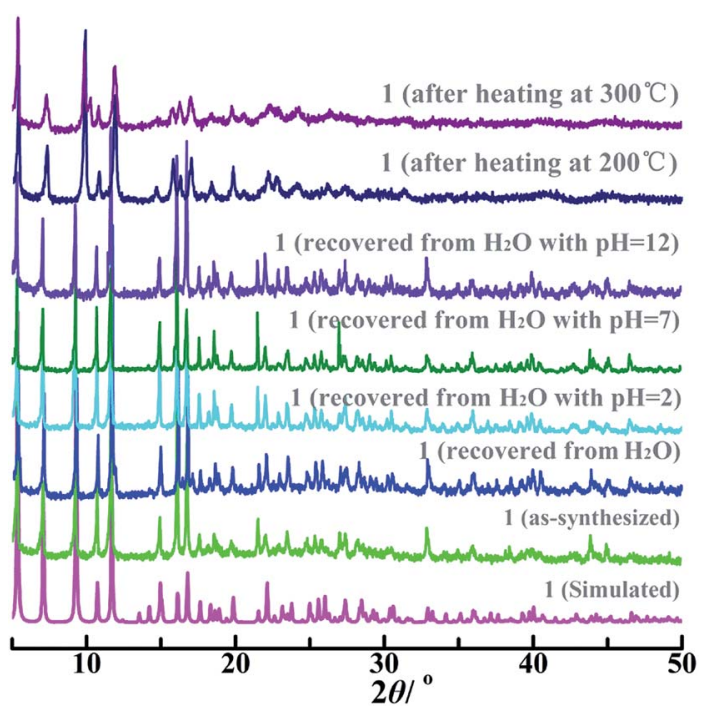

Fig. 2 PXRD patterns of simulated and as-synthesized 1 in different external environments. 
environmental stability, and can be potentially used as a chemical sensor.

\subsection{Emission spectra and energy transfer of 1}

Emission spectra of solid-state $\mathbf{1}$ and free $\mathrm{H}_{2}$ bpydb ligand were recorded at room temperature to evaluate the energy transfer pathway. Due to the intramolecular $\pi \rightarrow \pi^{*}$ or $n \rightarrow \pi^{*}$ transition, free $\mathrm{H}_{2}$ bpydb molecule displays a broad emission band centered at $518 \mathrm{~nm}$ upon excitation at $477 \mathrm{~nm}$ (Fig. 3a). The broad emission leads to an intense green fluorescence, and can be easily naked-eye visualized under the irradiation of $365 \mathrm{~nm}$ UV light (Fig. 3a inset). Upon excitation at $371 \mathrm{~nm}, 1$ shows five separate emission bands at 578, 593, 616, 650, and $698 \mathrm{~nm}$ corresponding to the characteristic ${ }^{5} \mathrm{D}_{0} \rightarrow{ }^{7} \mathrm{~F}_{J}(J=0-4)$ transitions of $\mathrm{Eu}^{\mathrm{III}}$ ion. The intense emission make 1 emit a naked eye-visualized red signal (Fig. 3a inset) with the quantum yield (QY) and lifetime $(\tau)$ of $5.38 \%$ and $477 \mu$ s monitored at $371 \mathrm{~nm}$ and $616 \mathrm{~nm}$. Notably, the emission intensity ratio of the electricdipole ${ }^{5} \mathrm{D}_{0} \rightarrow{ }^{7} \mathrm{~F}_{2}$ (616 nm) and magnetic-dipole ${ }^{5} \mathrm{D}_{0} \rightarrow{ }^{7} \mathrm{~F}_{1}$ (593 $\mathrm{nm}$ ) transitions is about 2.8, indicating that the $\mathrm{Eu}^{\mathrm{III}}$ ion in 1 occupies a low-symmetry coordination site with no inversion center $^{42}$ and is well consistent with the results of single-crystal $\mathrm{X}$-ray structural analysis. The ${ }^{5} \mathrm{D}_{0} \rightarrow{ }^{7} \mathrm{~F}_{2}$ transition has a large intensity comparable to that of the ${ }^{5} \mathrm{D}_{0} \rightarrow{ }^{7} \mathrm{~F}_{4}$ transition, suggesting that the intensity parameter $\Omega_{\lambda}$ is in a weak polarizable environment. ${ }^{\mathbf{4 3 - 4 5}}$ Additionally, the disappearance of the ligandcentered emission in 1 demonstrates that the bpydb $^{2-}$ anion acts as a good antenna ligand to efficiently sensitize the luminescence of the $\mathrm{Eu}^{\mathrm{III}}$ ion.

To deep insight into the energy transfer pathways between the bpydb $^{2-}$ ligand and $\mathrm{Eu}^{\text {III }}$ ion, excitation wavelengthdependent emissions of $\mathbf{1}$ were measured at room temperature, together with the $\tau$ values at $616 \mathrm{~nm}$ and excitation wavelength-dependent QY measurements. As shown in Fig. 3b, the emission intensity of 1 at $616 \mathrm{~nm}\left(I_{616}\right)$ gradually increases with the increasing excitation wavelengths from 325 to $370 \mathrm{~nm}$, while the QY decreases monotonously and $\tau$ values varies only slightly (Table S2 $\dagger$ ). Once the excitation light is beyond $370 \mathrm{~nm}$, the $I_{616}$ declines dramatically, accompanying with an appearance of a new broad band centered at $518 \mathrm{~nm}$ and apparently shortened lifetime at $616 \mathrm{~nm}$ (Fig. 3b inset and Table S2 $\dagger$ ). These observations reveal that the different energy transfer pathways occur between $\mathrm{Eu}^{\mathrm{III}}$ ion and bpydb ${ }^{2-}$ ligand. With the gradual decrease of the excitation energy, the $S_{1} \rightarrow S_{\mathrm{o}}$ transition of the bpydb ${ }^{2-}$ happens, accompanying the incomplete energy transfer from $T_{1}$ of the ligand to the ${ }^{5} \mathrm{D}_{0}$ state of the Eu ${ }^{\mathrm{III}}$ ion for the decreased fluorescence intensity at $616 \mathrm{~nm}$.

Since the UV light is strongly scattering and can significantly mutate cells and tissues responsible probably for premature aging or skin cancer, the low-energy excitation in the visible region is highly desirable and particularly significant for the clinical applications of the probes. Due to the favorable emission intensity of $\mathbf{1}$ in the visible region and the maximum absorption wavelength of bilirubin, $432 \mathrm{~nm}$ was then selected as the optimal excitation energy for the sensing investigations of 1 . It should be mentioned that the QY and $\tau$ values of 1 is $2.85 \%$ and $413 \mu \mathrm{s}$ upon excitation at $432 \mathrm{~nm}$ (Table S2 and Fig. S5 $\dagger$ ), slightly smaller than those of $\mathbf{1}$ excited at the optimal excitation wavelength $\left(\lambda_{\mathrm{ex}}=371 \mathrm{~nm}\right)$.

\subsection{Selective sensing of 1 towards bilirubin}

The intense red emission, robust stability and low-energy excitation motivate us to investigate the responsive ability of $\mathbf{1}$ to bilirubin in water system. Upon excitation at $432 \mathrm{~nm}$, the $I_{616}$ of 1 decrease to some different degree in the presence of different substances in the urine (Fig. 4a). Quenching efficiency of 1 defined as $\left(I_{0}-I\right) / I_{0} \times 100 \%$ is $95.7 \%$ by bilirubin, remarkably higher than the other components existing in the urine (7.9$27.0 \%$, Fig. 4 b). Thus, 1 can selectively distinguish bilirubin in the uniform dispersion through luminescent quenching. To quantitatively evaluate the quenching constant $\left(K_{\text {sv }}\right)$ by bilirubin, luminescence titration was carried out by incremental addition of bilirubin stock solution into the dispersion of 1 . As illustrated in Fig. 4c, the $I_{616}$ declines gradually with the gradually increasing bilirubin. When the concentration of bilirubin is $3.32,19.6$ and $56.6 \mu \mathrm{M}$, the $I_{616}$ of 1 is $15.4 \%, 57.4 \%$ and

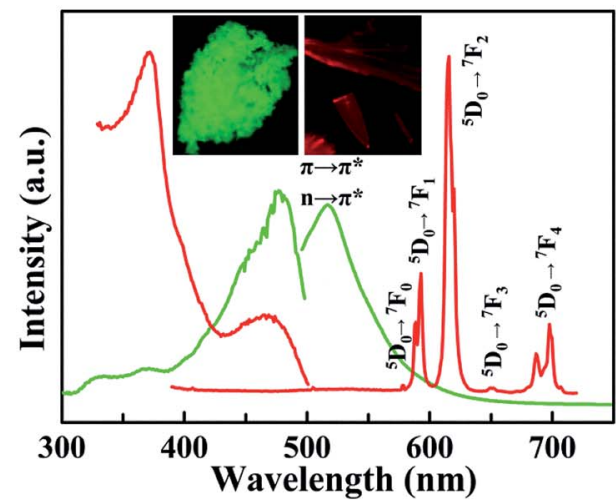

(a)

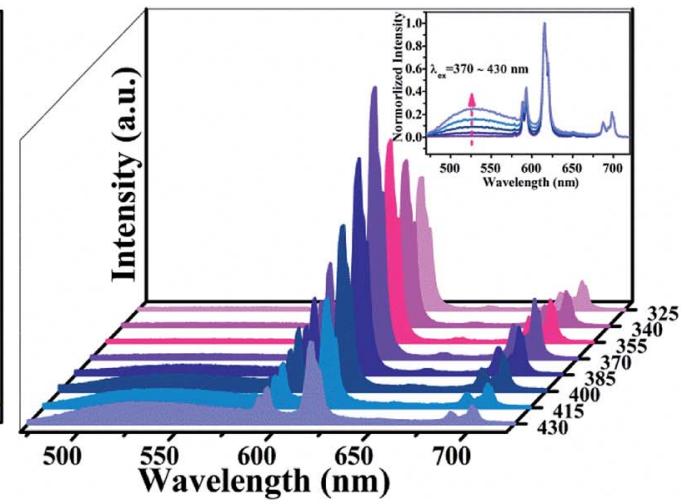

(b)

Fig. 3 (a) Solid-state excitation and emission spectra of 1 and free $\mathrm{H}_{2}$ bpydb molecule (inset: optical images of 1 and $\mathrm{H}_{2}$ bpydb). (b) Excitation wavelength-dependent emission spectra of 1 in the solid-state at room temperature. 


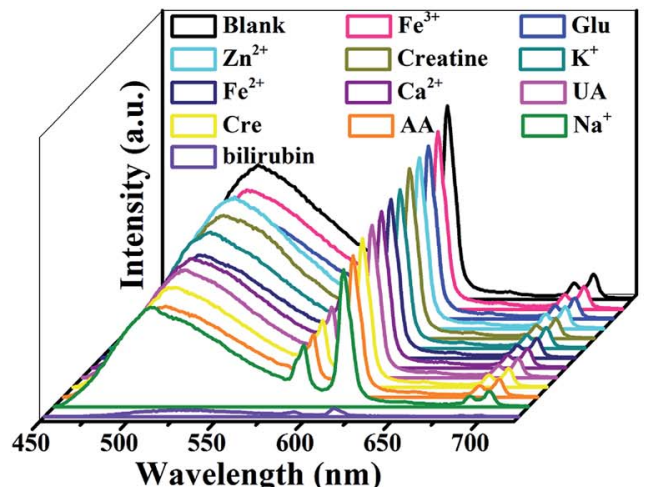

(a)

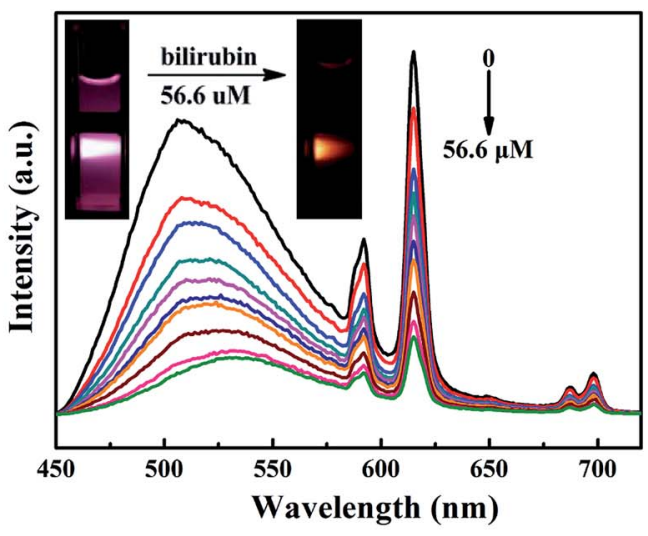

(c)

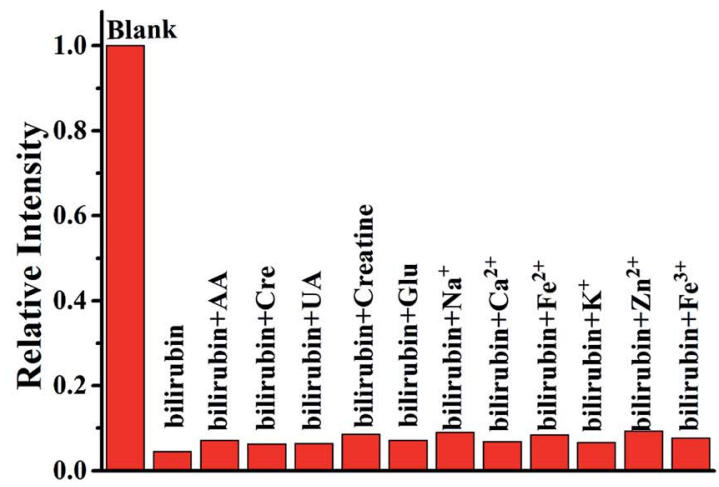

(e)

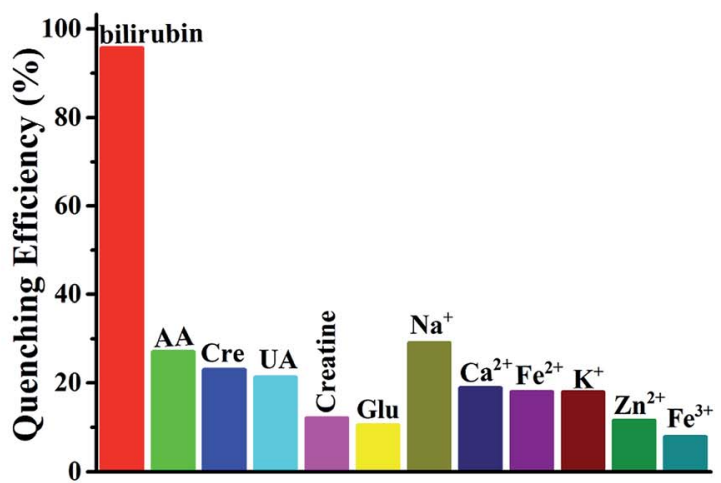

(b)

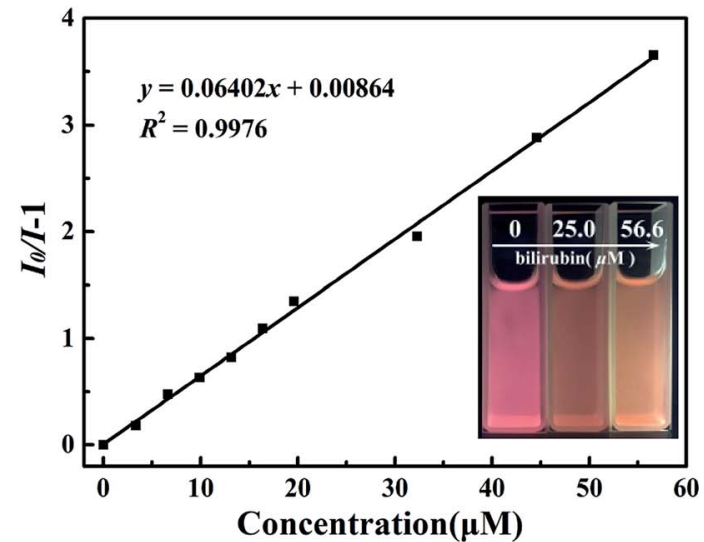

(d)

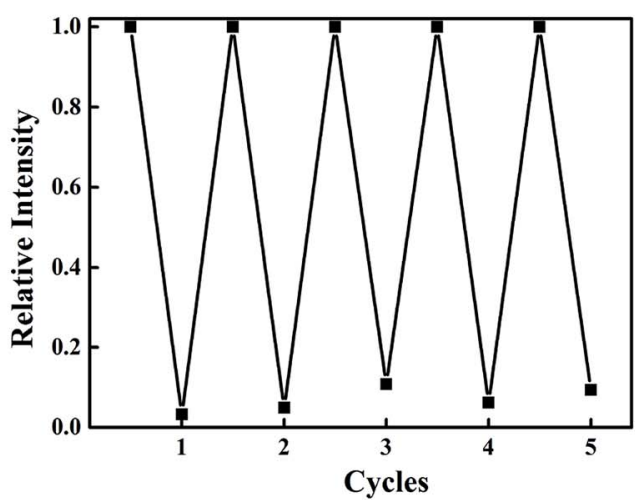

(f)

Fig. 4 (a) Emission spectra of 1 in the absence and presence of different components of urine. (b) Luminescent intensity of 1 suspension at $616 \mathrm{~nm}$ in the presence of different substances of urine. (c) Emission spectra of 1 in the presence of different concentrations of bilirubin. (d) Plot of $\left(I_{0} / I-1\right)$ vs. [bilirubin]. (e) Fluorescence response of 1 upon addition of bilirubin together with one of other interfering chemicals. (f) Recycling of 1 implemented with bilirubin aqueous solution.

$78.5 \%$ of its initial intensity. Moreover, apparent color change of the dispersion system can be easily observed by the naked eyes under the irradiations of $432 \mathrm{~nm}$ (Fig. $4 \mathrm{c}$ inset) and $365 \mathrm{~nm}$ of portable UV lamp (Fig. $4 \mathrm{~d}$ inset). The plot of $I_{0} / I v s$. [bilirubin] is straightly linear within the whole concentration range examined herein, suggesting a static quenching mechanism. The plot of $I_{0} / I v s$. [bilirubin] can be well fitted to the SternVolmer $(\mathrm{S}-\mathrm{V})$ equation $\left(I_{0} / I\right)=K_{\mathrm{sv}}[\mathrm{M}]+1$, in which $I_{0}$ and $I$ are luminescent intensity of $\mathbf{1}$ in the absence and presence of bilirubin, respectively; $[\mathrm{M}]$ is the molar concentration of bilirubin, and $K_{\mathrm{sv}}$ is the quenching constant $\left(\mathrm{M}^{-1}\right){ }^{41}$ The best fit affords $K_{\mathrm{Sv}}=6.40 \times 10^{4} \mathrm{M}^{-1}$ and an excellent correlation coefficient $R^{2}$ $=0.9976$. The $K_{\mathrm{sv}}$ of $\mathbf{1}$ towards bilirubin is slightly lower than that of the sole MOF sensor UIO-66-PSM (Table 3).$^{30}$ Moreover, as compared with UIO-66-PSM, 1 has two additional advantages: simple preparation (solvothermal synthesis vs. post- 
Table 3 Comparison for the reported luminescence probes for bilirubin

\begin{tabular}{|c|c|c|c|}
\hline Sensors & Linear range $/ \mu \mathrm{M}$ & $\mathrm{LOD} / \mathrm{nM}$ & $K_{\mathrm{sv}} / \mathrm{M}^{-1}$ \\
\hline BAMD $^{3}$ & $1 \times 10^{-6}-500$ & 0.0028 & $3.3 \times 10^{10}$ \\
\hline $\mathrm{HSA}^{-\mathrm{AuNCs}^{7}}$ & $1-50$ & $248 \pm 12$ & $5.5 \times 10^{5}$ \\
\hline S,N-CDs/Fe(III) ${ }^{15}$ & $0.2 \times 10^{-3}-2 \times 10^{-3}$ & 0.12 & - \\
\hline BSA-CuNCs/Fe ${ }^{3+}$ (ref. 16) & $0.1 \times 10^{-6}-0.1$ & 6.62 & - \\
\hline UIO-66-PSM ${ }^{30}$ & $0-500$ & 0.00059 & $8.95 \times 10^{4}$ \\
\hline
\end{tabular}

synthetic modfication) and visible light excitation $\left(\lambda_{\mathrm{ex}}=432 \mathrm{~nm}\right.$ vs. $\lambda_{\mathrm{ex}}=340 \mathrm{~nm}$ ). Additionally, although possessing larger $K_{\mathrm{sv}}$ values than that of $\mathbf{1}$ (Table 3 ), the sensing of both BAMD and HSA-AuNCs towards bilirubin occurred under the excitation of UV light, which has severely restricted their clinical application and can not be easily observed by naked-eye.

Limit of detection (LOD) is also an important parameter that describes the sensing ability of the sensor. The LOD of 1 towards bilirubin is $1.75 \mu \mathrm{M}$ calculated from the equation LOD $=3 \sigma / k$, wherein $\sigma$ is the standard deviation of five separate blank measurements and $k$ is the slope extracted from the plot of $I$ vs. [bilirubin] (Fig. S6 $\dagger$ ). The LOD of 1 is much lower than the safety content of bilirubin in the human serum, but much higher than that of UIO-66-PSM and other types of sensors (Table 3$).{ }^{30}$ Therefore, much efforts should be specially paid on the improvement of the LOD, in which the enhancement of $\sigma$ is much more important than that of $k$.

To evaluate the sensing specificity of 1 towards bilirubin in the practical applications, the potential influences from the interfering biomolecules and metal cations in the urine on the sensing behavior were considered. As demonstrated in Fig. 4e, the fluorescence quenching effect of $\mathbf{1}$ by bilirubin is almost comparable to those caused by bilirubin and one of the interfering substances including UA, Cre, AA, Creatine, Glu, $\mathrm{Na}^{+}$, $\mathrm{Fe}^{2+}, \mathrm{Zn}^{2+}, \mathrm{K}^{+}, \mathrm{Ca}^{2+}$ and $\mathrm{Fe}^{3+}$. These observations show that $\mathbf{1}$ can discriminate bilirubin in a highly selective and sensitive manner without being disturbed by other components in the urine sample.

The recyclable performance of $\mathbf{1}$ on the response of bilirubin was also checked. After at least five continuous sensing recycles, both the luminescence intensity and PXRD pattern of the recovered 1 were almost the same as those of the original sample (Fig. 4f and $\mathrm{S} 7 \dagger$ ). Response rate and discrimination stability of 1 to bilirubin in physiological conditions were also explored. For the physiological $\mathrm{pH}$-responsive behavior, $1.0 \mathrm{mg}$ of 1 was added to $3.0 \mathrm{~mL}$ water with $\mathrm{pH}=4-8$ adjusted by $\mathrm{HCl}$ or $\mathrm{NaOH}$ and the emission spectra of $\mathbf{1}$ is the similar to each other and the $I_{616}$ is thus pH-independent (Fig. S8 $\dagger$ ). Moreover, the fluorescence intensity of $\mathbf{1}$ decreases rapidly within two seconds upon contacting with bilirubin in aqueous solution with $\mathrm{pH}=7.4$, and the decayed intensity can keep constant for two min (Fig. S9†). Therefore, 1 can serve as a superior chemical sensor for bilirubin with multiple advantages of fast response, good recycling, robust stability, high selectivity and sensibility.

\subsection{Sensing mechanism}

To deep understand the responsive mechanism, PXRD patterns, FT-IR spectra and fluorescence lifetimes of $\mathbf{1}$ were investigated before and after bilirubin sensing, together with the UV-vis absorption of all the examined analytes. Both PXRD patterns and FT-IR spectra of 1 remain consistent before and after the sensing experiments (Fig. 5a and b), confirming the quenching is not caused by the framework collapse, ion exchange, as well as the strong interactions between $\mathbf{1}$ and bilirubin. Additionally, the $\tau$ value of 1 at $616 \mathrm{~nm}$ is only slightly shortened from 370 to $337 \mu$ s after addition of bilirubin $\left(180 \mu \mathrm{L}, 1.0 \times 10^{-3} \mathrm{~mol} \mathrm{~L}^{-1}\right.$, Fig. 5c), suggesting that a static quenching mechanism occurred during the discrimination process, not any Förster resonance energy transfer (FRET). ${ }^{46}$

To further confirm the possibility of the inner filter effect and photoinduced charge transfer (PET) between 1 and bilirubin, the UV-vis absorption spectra and Mott-Schottky curve were measured, respectively. As shown in Fig. 5d, bilirubin displays a broad absorption centered at $432 \mathrm{~nm}$ among the UVvis absorption spectra of the twelve analytes examined herein, which overlaps well with the excitation spectrum of 1 . Therefore, both bilirubin and $\mathbf{1}$ can effectively absorb the excitation energy, and the more favorable absorption of bilirubin towards the excitation light than 1 can weaken the energy transfer efficiency from bpydb ${ }^{2-}$ to $\mathrm{Eu}^{\mathrm{III}}$, resulting in the quenching of characteristic luminescence of $\mathrm{Eu}^{\mathrm{III}}$ ion in 1. To eliminate the influence of inner filter effect (IFE) on the fluorescent decrease, the IFE correction was further considered with through Parker equation. The observed and corrected quenching efficiency ( $E_{\text {obsd }}$ and $E_{\text {cor }}$ ) were respectively obtained as $78.5 \%$ and $34.4 \%$ (Table S3, Fig. S10 and S11 $\dagger$ ). Thus, the quenching cause by IFE and PET mechanism are about $44.1 \%$ and $34.4 \%$, respectively.

The PET process can be further analyzed by comparing the energy levels of $\mathbf{1}$ and bilirubin. The band gap extracted from the UV-vis diffuse reflectance spectra is $3.24 \mathrm{ev}$ and $2.58 \mathrm{eV}$ for 1 and bilirubin (Fig. S12 $\dagger$ ). The flat band potential determined from the intersection is approximately $-1.30 \mathrm{~V}(v s . \mathrm{Ag} / \mathrm{AgCl})$ and $-1.10 \mathrm{~V}$ (vs. NHE) for 1 as well as $-1.05 \mathrm{~V}(v s$. $\mathrm{Ag} / \mathrm{AgCl})$ and $-0.85 \mathrm{~V}$ ( $v s$. NHE) for bilirubin (Fig. 5e). According to their band gap values, the valence band potential is calculated to be $2.14 \mathrm{~V}$ and $1.73 \mathrm{~V}$ ( $v s$. NHE) for 1 and for bilirubin. The work function $(E)$ of 1 and bilirubin $v s$. vacuum can be obtained using equation $E(\mathrm{eV})=-4.5-E_{\mathrm{NHE}}(\mathrm{V}) .{ }^{47}$ Considering the conduction band potentials of 1 and bilirubin are $-3.40 \mathrm{eV}$ and $-3.65 \mathrm{eV}$, 


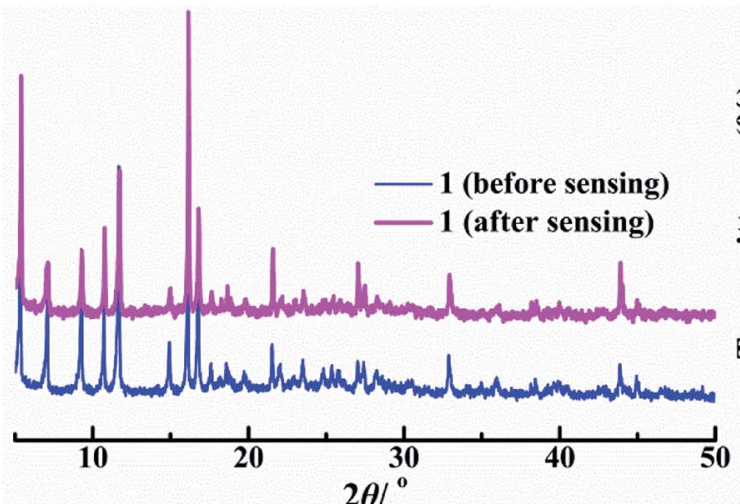

(a)

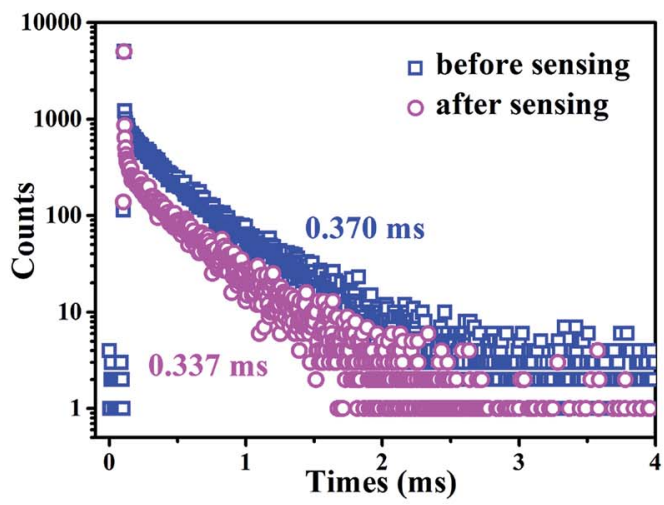

(c)

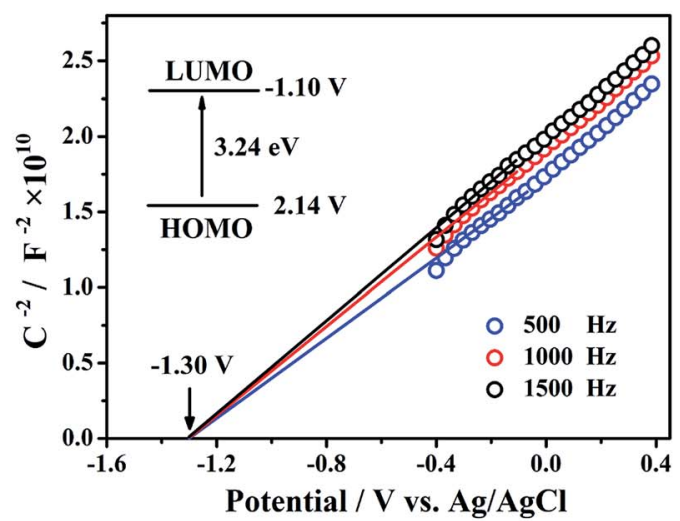

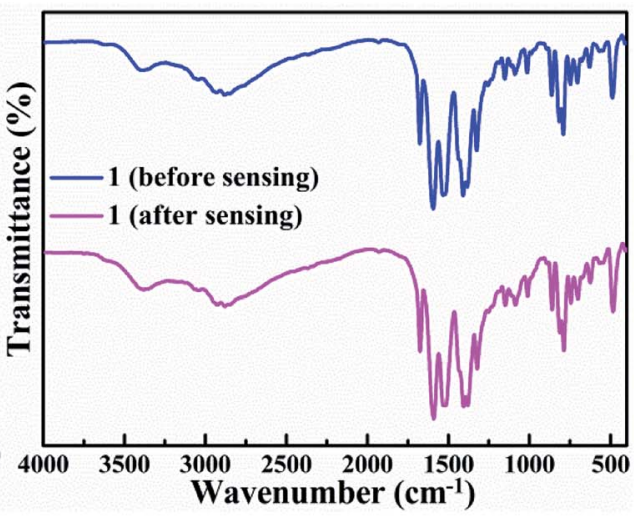

(b)

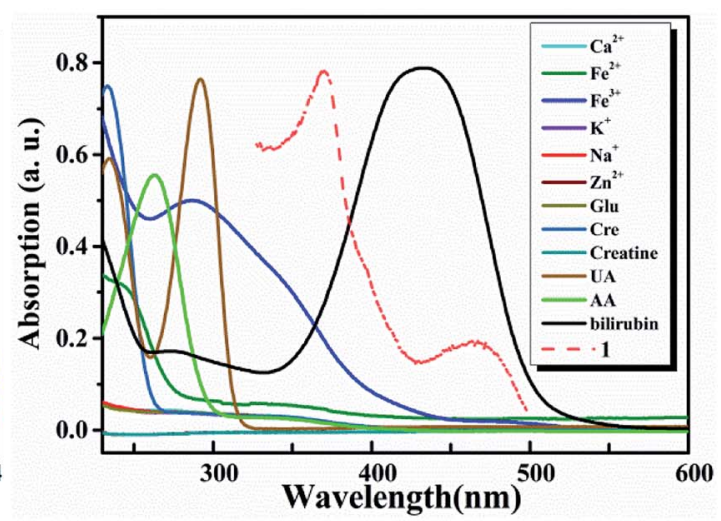

(d)

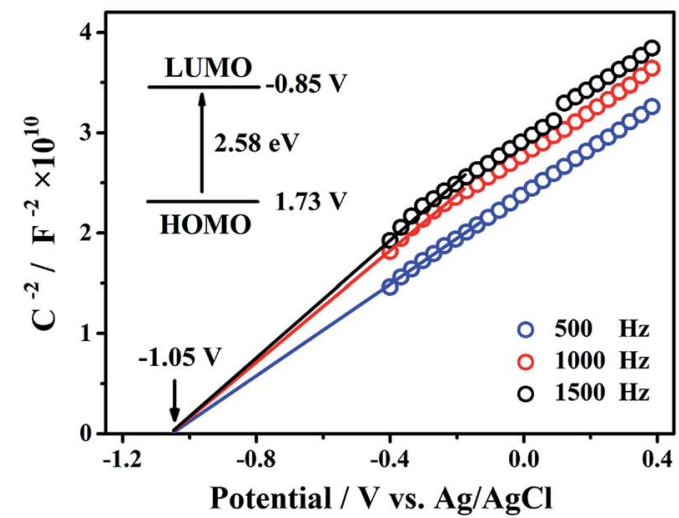

(e)

Fig. 5 (a) PXRD patterns of 1 before and after bilirubin sensing. (b) FT-IR spectra of 1 before and after bilirubin response. (c) Time-resolved decay curves of 1 at $616 \mathrm{~nm}$ in the absence and presence of bilirubin. (d) UV-vis absorption spectra of different bio-molecules and metal ions in aqueous solution and excitation spectrum of 1. (e) Mott-Schottky curves and energy band positions of 1 and bilirubin.

a direct PET from 1 to bilirubin can easily occur, responsible for the decay of the 1 at $616 \mathrm{~nm}$. Thus, the competition of absorption between bilirubin and ligand in $\mathbf{1}$ and PET from 1 to bilirubin should be jointly responsible for the selective and sensitive detecting of bilirubin in water system.

\subsection{Fluorescence test paper of 1}

A portable and economic test paper was designed to advance the bilirubin response of $\mathbf{1}$ more simple and more feasible. The as- prepared test papers were soaked in aqueous bilirubin solutions with different concentrations for 30 second and then exposed under the UV lamp of $365 \mathrm{~nm}$. As shown in Fig. 6, the luminescent color of the paper exhibited intense red in the absence of bilirubin observed by the naked eyes. With the increasing amounts of the bilirubin from 0 to $500 \mu \mathrm{M}$, the color of the test paper changed quickly and become darker and darker upon exposure of the UV lamp, which are suitable for hands on use. Thus, the portable test paper can be used as a promising 


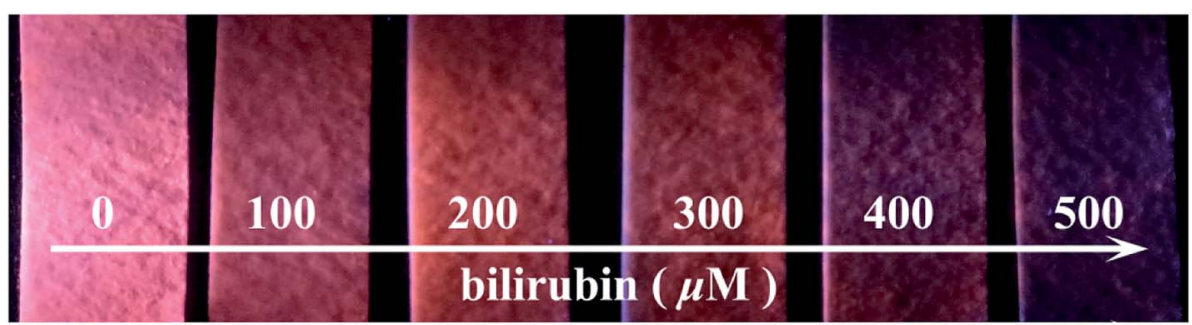

Fig. 6 Optical images of 1-coated test papers in the absence and presence of aqueous bilirubin solution under the irradiation of $365 \mathrm{~nm}$ UV lamp.

luminescent sensor for the diagnosis of jaundice detection in a simple and quick manner.

\section{Conclusions}

A highly robust europium(III)-organic framework with bent chains cross-linked by $\pi$-extended $4,4^{\prime}$-(4,4'-bipyridine-2,6-diyl) dibenzoate connectors was solvothermally generated and structurally characterized. Resulting significantly from the inferior absorption of antenna ligand towards the irradiated light and photoinduced electron transfer from the sensor to bilirubin, the framework with intense red luminescent can quickly and repeatedly detect bilirubin in water system through fluorescence decay with strong quenching constant up to $6.40 \times$ $10^{4} \mathrm{M}^{-1}$ and low LOD down to $1.75 \mu \mathrm{M}$. More interestingly, a portable test paper prepared from the sensor was developed, providing visual detection of bilirubin by naked eyes in the feasible applications. These interesting results demonstrate the significance of the antenna ligand with $\pi$-conjugated skeleton on the promising luminescent sensors in the clinical diagnosis of jaundice.

\section{Conflicts of interest}

There are no conflicts to declare.

\section{Acknowledgements}

Financial supports were from the NSFC (grants 21671149, 21571140 and 21531005), the 973 Program (2014CB845601) and the Program for Innovative Research Team in University of Tianjin (TD13-5074), which were gratefully thanked.

\section{References}

1 C.-F. Ma, Q. Gao, J. Zhou, Q.-X. Chen, B. Han, K.-S. Xia and C.-G. Zhou, RSC Adv., 2017, 7, 2081-2091.

2 A. T. Lee, Y. Y. Wang, S. Y. Lin, J. T. Liang, W. H. Sheu, Y. M. Song and W. D. Chang, Int. J. Clin. Exp. Med., 2015, 8, 19212-19222.

3 S. Ellairaja, K. Shenbagavalli, S. Ponmariappan and V. S. Vasantha, Biosens. Bioelectron., 2017, 91, 82-88.

4 L. Lam, S. Musaad, C. Kyle and S. Mouat, Clin. Chem., 2017, 63, 973-979.
5 Q. L. Feng, Y. L. Du, C. Zhang, Z. X. Zheng, F.-D. Hu, Z. H. Wang and C. M. Wang, Sens. Actuators, B, 2013, 185, 337-344.

6 S.-K. Chou and M.-J. Syu, Biomaterials, 2009, 30, 1255-1262.

7 M. Santhosh, S. R. Chinnadayyala, A. Kakoti and P. Goswami, Biosens. Bioelectron., 2014, 59, 370-376.

8 C. E. Ahlfors, Anal. Biochem., 2000, 279, 130-135.

9 J. Fevery, Liver Int., 2008, 28, 592-605.

10 Y. Morimoto, T. Ishihara, M. Takayama, M. Kaito and Y. Adachi, J. Clin. Lab. Anal., 2000, 14, 27-31.

11 M. Ameri, H. Schnaars, J. Sibley and D. Honor, J. Vet. Diagn. Invest., 2011, 23, 120-123.

12 M. Santhosh, S. R. Chinnadayyala, N. K. Singh and P. Goswami, Bioelectrochemistry, 2016, 111, 7-14.

13 W. Yang, J. F. Xia, G. H. Zhou, D. Y. Jiang and Q. Li, RSC Adv., 2018, 8, 17854-17859.

14 Y. Andreu, M. Ostra, C. Ubide, J. Galbán, S. De Marcos and J. R. Castillo, Talanta, 2002, 57, 343-353.

15 R. R. Anjana, J. S. Anjali Devi, M. Jayasree, R. S. Aparna, B. Aswathy, G. L. Praveen, G. M. Lekha and G. Sony, Microchim. Acta, 2018, 185, 1-11.

16 M. Jayasree, R. S. Aparna, R.-R. Anjana, J. S. Anjali Devi, N. John, K. Abha, A. Manikandan and S. George, Anal. Chim. Acta, 2018, 1031, 152-160.

17 Y. J. Cui, B. L. Chen and G. D. Qian, Coord. Chem. Rev., 2014, 273, 76-86.

18 J. Rocha, L. D. Carlos, F. A. A. Paz and D. Ananias, Chem. Soc. Rev., 2011, 40, 926-940.

19 J. M. Zhou, H. H. Li, H. Zhang, H. M. Li, W. Shi and P. Cheng, Adv. Mater., 2015, 27, 7072-7077.

20 M. D. Allendorf, C. A. Bauer, R. K. Bhakta and R. J. T. Houk, Chem. Soc. Rev., 2009, 38, 1330-1352.

21 T.-Y. Luo, C. Liu, S. V. Eliseeva, P. F. Muldoon, S. Petoud and N. L. Rosi, J. Am. Chem. Soc., 2017, 139, 9333-9340.

22 B. L. Chen, L. B. Wang, F. Zapata, G. D. Qian and E. B. Lobkovsky, J. Am. Chem. Soc., 2008, 130, 6718-6719.

23 W. P. Lustig, S. Mukherjee, N. D. Rudd, A. V. Desai, J. Li and S. K. Ghosh, Chem. Soc. Rev., 2017, 46, 3242-3285.

24 K. Shi, Z. Yang, L. Dong and B. Yu, Sens. Actuators, B, 2018, 266, 263-269.

25 S. Wu, Y. Lin, J. Liu, W. Shi, G. Yang and P. Cheng, Adv. Funct. Mater., 2018, 28, 1707169.

26 J. Zhang, T. F. Xia, D. Zhao, Y. J. Cui, Y. Yang and G. D. Qian, Sens. Actuators, B, 2018, 260, 63-69. 
27 X. B. Zheng, R. Q. Fan, Y. Song, K. Xing, P. Wang and Y. L. Yang, ACS Appl. Mater. Interfaces, 2018, 10, 3269832706.

28 X.-Z. Song, S.-Y. Song, S.-N. Zhao, Z.-M. Hao, M. Zhu, X. Meng, L.-L. Wu and H.-J. Zhang, Adv. Funct. Mater., 2014, 24, 4034-4041.

29 G. G. Tang, J. Gao, C. H. Wang and H. L. Tan, Sens. Actuators, $B, 2017,244,571-576$.

30 Y. R. Du, X. Q. Li, X. J. Lv and Q. Jia, ACS Appl. Mater. Interfaces, 2017, 9, 30925-30932.

31 M.-Y. Sun, D.-M. Chen and H. Zhang, Inorg. Chem. Commun., 2016, 73, 103-106.

32 G. M. Sheldrick, $S A D A B S$, University of Göttingen, Göttingen, Germany, 1996.

33 A. X. S. Bruker, SAINT software Reference Manual, Madison, WI, 1998.

34 (a) G. M. Sheldrick, SHELXL-97, Program for X-ray Crystal Structure Refinement, Göttingen University, Göttingen, Germany, 1997; (b) G. M. Sheldrick, SHELXS-97, Program for X-ray Crystal Structure Solution, Göttingen University, Göttingen, Germany, 1997; (c) G. M. Sheldrick, Acta Crystallogr., Sect. A: Cryst. Phys., Diffr., Theor. Gen. Crystallogr., 2015, 71, 3-8; (d) G. M. Sheldrick, Acta Crystallogr., Sect. C: Struct. Chem., 2015, 71, 3-8.

35 A. L. Spek, Acta Crystallogr., Sect. D: Biol. Crystallogr., 2009, 65, 148-155.

36 W. Gu, X. Pei, Y. Cheng, C. Zhang, J. Zhang, Y. Yan, C. Ding and Y. Xian, ACS Sens., 2017, 2, 576-582.

37 A. S. Tanwar, L. R. Adil, M. A. Afroz and P. K. Iyer, ACS Sens., 2018, 3, 1451-1461.
38 M. Llunell, D. Casanova, J. Cirera, P. Alemany and S. Alvarez, SHAPE, v2.1, University of Barcelona and the Hebrew University of Jerusalem, Barcelona and Jerusalem, 2013.

39 Z.-H. Zhang, Y. Song, T. Okamura, Y. Hasegawa, W.-Y. Sun and N. Ueyama, Inorg. Chem., 2006, 45, 2896-2902.

40 D. Zhao, D. Yue, L. Zhang, K. Jiang and G. D. Qian, Inorg. Chem., 2018, 57, 12596-12602.

41 S. Xu, J.-J. Shi, B. Ding, Z.-Y. Liu, X.-G. Wang, X.-J. Zhao and E.-C. Yang, Dalton Trans., 2019, 48, 1823-1834.

42 S. I. Klink, L. Grave, D. N. Reinhoudt, F. C. J. M. van Veggel, M. H. V. Werts, F. A. J. Geurts and J. W. Hofstraat, J. Phys. Chem. A, 2000, 104, 5457-5468.

43 R. A. Sá Ferreira, S. S. Nobre, C. M. Granadeiro, H. I. S. Nogueira, L. D. Carlos and O. L. Malta, J. Lumin., 2006, 121, 561-567.

44 C. J. Höller, P. R. Matthes, M. Adlung, C. Wickleder and K. Müller-Buschbaum, Eur. J. Inorg. Chem., 2012, 33, 54795484.

45 Y. Q. Wei, R. J. Sa, Q. H. Lia and K. C. Wu, Dalton Trans., 2015, 44, 3067-3074.

46 F. Y. Yan, F. L. Zu, J. X. Xu, X. G. Zhou, Z. J. Bai, C. Ma, Y. M. Luo and L. Chen, Sens. Actuators, B, 2019, 287, 231-240.

47 (a) R. Czerw, B. Foley, D. Tekleab, A. Rubio, P. M. Ajayan and D. L. Carroll, Phys. Rev. B: Condens. Matter Mater. Phys., 2002, 66, 033408; (b) R. Memming, Top. Curr. Chem., 1994, 169, 105-181; (c) M. Sadeghi, W. Liu, T.-G. Zhang, P. Stavropoulos and B. Levy, J. Phys. Chem., 1996, 100, 19466-19474. 